\section{An Essential Contribution to Physical Chemistry}

\author{
by Nikolay O. Mchedlov-Petrossyan
}

\section{$\mathrm{T}$}

he V.N. Karazin National University, formerly Kharkov State University, has a long-standing tradition in physical chemistry dating back almost 150 years, ${ }^{1}$ in which the renowned Russian chemist, Nikolai Beketov (1827-1911), played a pioneering role. As early as 1860 , he took the first initiative in a series of lectures entitled "Special Course of Organic Chemistry and Interrelation Between Physical and Chemical Phenomena." Within a few years a decisive milestone was reached when he founded the Physico-Chemical Division of the University in 1864 and delivered the first course of lectures on physical chemistry in 1865.

During the last years of the 19th century and the early years of the 20th century, a succession of scientists-among them P.D. Khrushchov, V.F. Timofeyev, N.D. Pilchikov, D.P. Turbaba, and G.E. Timofeyevplayed a major role in building the university's reputation and contributing significantly to the field of physical chemistry, mainly in the specialized area of solution chemistry. This tradition was continued in the years before the outbreak of World War II, with a succession of outstanding physical chemists in Kharkov. Along with the notable achievements of G.E. Mukhin, A.N. Shchukarev, I.S. Teletov, P.P. Kosakevitch, E.N.

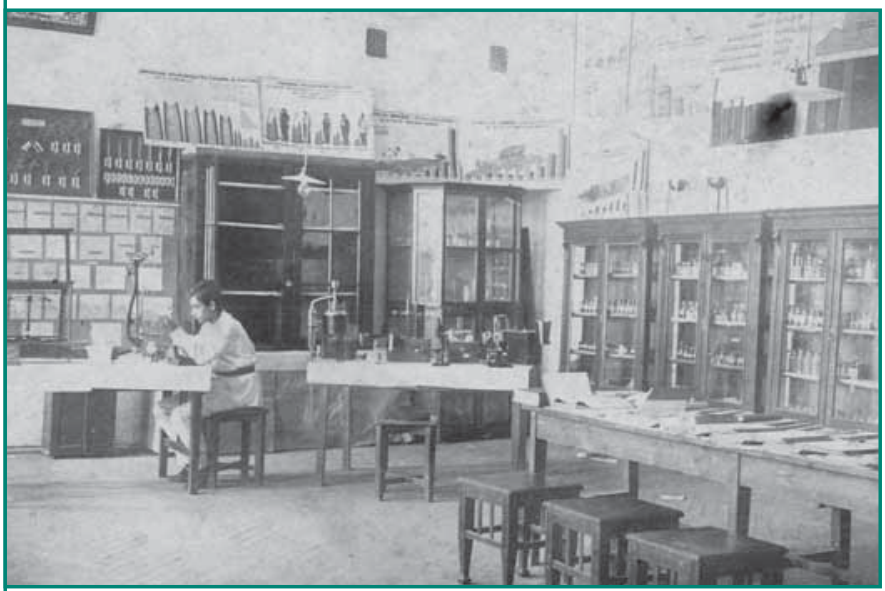

Young Nikolai Izmailov in the chemical laboratory of the Financial-Economical Technical School.
Gapon, S.S. Urazovskiy, and I.N. Frantsevich, the career foundation of Nikolai Arkadievich Izmailov was laid at this time, before he went on to head the Department of Physical Chemistry of the Kharkov State University from 1944 to 1961.

Nikolai Izmailov (1907-1961) was born in Sukhumi in the southern region of the Russian Empire on 22 June 1907. During his early years he endured hardships, which most certainly contributed to his personal growth and maturation into what can aptly be characterized as a self-made man. When Nikolai was two years old, his father died. At the outbreak of the October Revolution in 1917, the family happened to be in Kharkov, and at the tender age of 10 Nikolai was obliged to assume the mantle of responsibility as the senior male member of the family and to support his mother, grandmother, and sister. Thus, he started a battle for survival in the face of daunting obstacles.

Despite these demands, he was able to persevere with his education and enrolled at the FinancialEconomical Technical School in 1922. Here he was first introduced to chemistry and developed a deep and enduring interest in the discipline that was destined to shape his future. After graduating in 1926 he took a teaching position in a primary school, which gave him the opportunity to provide elementary instruction in chemistry. In the first formal step of his subsequent scientific career, in 1928 Izmailov enrolled as a Ph.D. student at Kharkov State University (at that time called the Kharkov Institute of Public Education). He initially conducted research, under the guidance of Professor Kosakevitch,2a into sorption of gases. Thereafter, he investigated the influence of salts on adsorption of organic molecules on the interface between water and air. ${ }^{2 b}$

Shortly after these introductory ventures, Izmailov began to pursue independent research activities. In 1934 he started on a joint appointment at Kharkov Pharmaceutical Research Institute, and his scientific interests developed along two main directions: static and dynamic properties of sorption from solutions, and the influence of the solvent on dissociation of electrolytes. Both of these branches of pure chemistry were driven by the needs of applied science. Furthermore, his lively inventiveness and scientific insight enabled him to recognize and pursue inquiries to a practical outcome. This is vividly exemplified by his search for new methods for pharmaceutical analysis in which he collaborated with Maria Shraiber to introduce in 1938 the "drop-chromatographic method,"3 which later became known as thin-layer chromatography. This 
finding is widely recognized and acclaimed and continues to play an essential role in everyday laboratory practice.

Izmailov was awarded a Ph.D. in chemistry at Kharkov State University in 1937. Shortly thereafter he made a start in his Sc.D. dissertation; however, the outbreak of World War II forced him to postpone any plans to complete and submit it. In October 1941, Izmailov, along with his wife and two children, were evacuated to his birthplace, Sukhumi, where they remained for the next three years. This was a period in which he was engaged in hard work for the needs of defense. After the liberation of Kharkov from the Germans in 1943, Izmailov received a government decree to return to the city and head the Department of Physical Chemistry at the university. In May 1944, the Izmailov family returned.

A long and difficult period of restoration followed because Kharkov had suffered extensive destruction during the conflict and occupation of 1941 through 1943. However, Izmailov managed to reconcile his duties as department head with his research in the Pharmaceutical Institute. He resumed work on the preparation of his Sc.D. dissertation, entitled "The Influence of Solvents on the Strength of Acids," which he eventually presented in January 1948 to the Ukrainian Academy of Sciences in Kiev. Later in the same year he was appointed a professor.

This was the start of an extraordinarily creative phase in Izmailov's career. A review on the subject of his dissertation 4 and his systematic studies throughout the 1950s, dealing with behavior of electrolytes in solution, provided the basis for the definitive understanding of dissociation at that time. ${ }^{5}$ His most monumental contribution was the treatise Electrochemistry of Solutions, which was published in Russian in 1959.6 Major sections of this voluminous 958-page workdevoted to the detailed scheme of electrolytic dissociation, differentiation action of solvents, and solvation, among other topics-were completely reviewed in the excellent monograph by A.l. Shatenshtein, which was translated into English7 and thus became available to international readership.5a This major contribution is well known to those working in the field of solution chemistry and is still frequently cited.

Izmailov also continued his early studies on the behavior of glass electrodes in different solvents and made notable contributions to the theory of physicochemical analysis. He authored more than 280 scientific publications during his career and supervised 31 people in their Ph.D. degree studies.

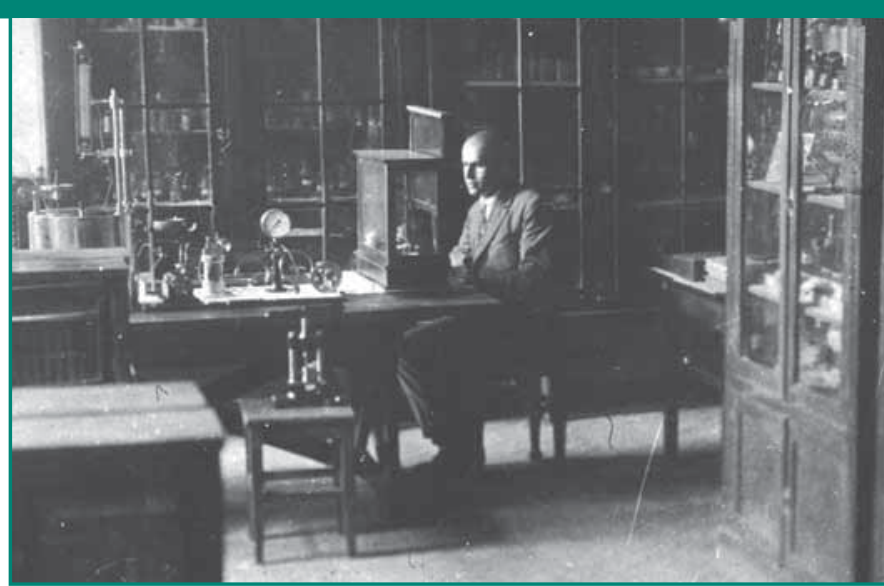

Izmailov in his laboratory in the 1930s.

Eleven of his coworkers later received Sc.D. degrees (V.N. Eremenko, A.M. Shkodin, V.D. Bezugliy, V.V. Aleksandrov, E.F. Ivanova, E.V. Titov, Yu.A. Krugliyak, O.M. Konovalov, V.P. Georgievskiy, V.I. Lebed, and V.D. Chmil). In 1955 the title "Honored Scientist of Ukraine" was conferred upon him, and in 1957 he was elected to the Academy of Sciences of the Ukrainian Soviet Republic. He was also honored by the Mendeleyev award for Electrochemistry of Solutions. ${ }^{6}$ In 1973, in recognition of his achievements in the field of glass electrode studies, he was posthumously included into the group of U.S.S.R. state prize winners.

Izmailov died suddenly on 2 October 1961 as he was discussing scientific problems with one of his coworkers. His untimely death while thus absorbed in his work is perhaps an expression of the man and his scientific style. He always believed that there was no time to be lost and usually began his working day at 5:00 a.m. He spent much time in consultation with his Ph.D. students and coworkers and also maintained regular sittings of scientific seminars in the physical chemistry department. Although he worked tremendously hard and was clearly driven by a consuming interest in science, he also led an active social life. He also was an enthusiastic sportsman and particularly enjoyed swimming, alpinism, and tennis. Among his extramural interests, he authored a set of publications devoted to the history of physical chemistry in Kharkov University. He also served the university as vice-rector from 1948 to 1953. In addition, Izmailov and his wife Alexandra Izmailova (Glukhovtseva) had a daughter, Victoria, and a son, Alexander. Victoria Nikolaevna Izmailova (1930-2002) spent a significant part of her career at Moscow State University, where she became a professor and was a well-known expert in the field of colloid chemistry. Alexander Nikolaevich (1938-1990) was a physicist. 
An International Conference on Modern Physical Chemistry for Advanced Materials was held in V.N. Karazin National University 26-30 June 2007 to commemorate the centenary of the birth of Professor Nikolai Izmailov. This event was held under the sponsorship of IUPAC and the European Society of Chemical and Molecular Sciences. Just before the opening of the conference, the book Scientific Heritage of N.A. Izmailov and Topical Problems of Physical Chemistry (eds. V.I. Lebed, N.O. MchedlovPetrossyan, Yu.V. Kholin, Kharkov University Press, Kharkov, 2007) was ceremonially presented to the academic community and the media at the Kharkov National University Museum.

The conference provided an opportunity to pay tribute to Nikolai Izmailov and to salute his achievements. A majority of the eminent international scientists who delivered plenary lectures at this event

Nikolai Izmailov (1907-1961) have contributed works to a collection of papers in Pure and Applied Chemistry [2008, Vol. 80, Issue 7; <www.iupac.org/ publications/pac/80/7/>]. This volume serves as a permanent archival record of the event and of the man who inspired it.

Supplementary material. A short bibliography listing the sources of some seminal contributions by N.A. Izmailov, analysis of his scientific activities written in English and in Russian, as well as some recollections are available at <www-chemistry.univer.kharkov.ua/ izmailov>.
Acknowledgements. The author is grateful to his mother, Nora N. Mchedlova-Petrossyan, who helped translate this essay into English. Acknowledgement is also due to James Bull, Pure and Applied Chemistry scientific editor, for his collaboration in the preparation of the PAC issue mentioned above and for critical review of this feature.

\section{References}

1. N.O. Mchedlov-Petrossyan. Chemical Intelligencer 3 (4), 41-45 (1997).

2. (a) P.P. Kozakewitsch, N. A. Izmailow. Koll. Z. 48, 241 (1929); idem, ibid. 57, 294 (1931); (b) P.P. Kozakewitsch, N. A. Izmailow. Z. Phys. Chem. Abt. A. 150, 295 (1930)

3. N.A. Izmailov, M.S. Shraiber. Farmatsia. No. 3, 1 (1938).

4. N.A. Izmailov. Zh. Fiz. Khim. 24, 321 (1950).

5. (a) J.A. Riddick. Anal. Chem. 32, 172 R (1960). (b) M.M. Davis. Acid-Base Behavior in Aprotic Organic Solvents. NBS Monograph 105: Washington, 1968, 151 p. (c) E. Bosch, M. Rosés. Anal. Chem. 60, 2008 (1988). (d) O. Budevski. Talanta 36, 1209 (1989). (e) C. Reichardt. Solvents and Solvent Effects in Organic Chemistry, 3rd ed., Wiley-VCH Verlag: Weinheim, 2003.

6. N.A. Izmailov. Electrochemistry of Solutions, Kharkov University Press: Kharkov, 1959; 2nd ed.: Khimiya: Moscow, 1966; 3rd ed.: ibid., 1976.

7. A.I.Shatenshtein. Isotopic Exchange and the Replacement of Hydrogen in Organic Compounds (authorized translation from the 1960 Russian edition by C.N. Turton and T.L. Turton), Consultants Bureau: New York, 1962.

Nikolay 0. Mchedlov-Petrossyan <mchedlov@univer.kharkov.ua> is head of the Department of Physical Chemistry, V.N. Karazin National University, in Kharkov, Ukraine.

\section{2nd IUPAC Congress-Chemistry Solutions Glasgow, Scotland, UK I 31 Julu-6 August 2009 | www.iupac2009.org}
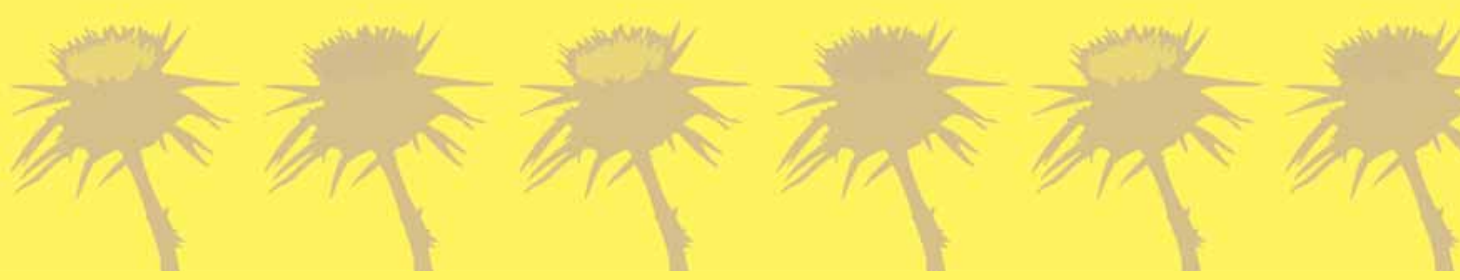